\title{
Background and Significance of the Construction of Hezhou University Language Museum
}

\author{
Zongyan Liu \\ School of Culture and Communication of Hezhou University, Hezhou Guangxi, 542899, China
}

Keywords: Language resource, Language museum, Hezhou University.

\begin{abstract}
Languages and dialects are valuable intangible cultural heritage, and economic globalization and integration directly are eroding this precious heritage, constituting two opposit sides of a contradictory. Building a language museum can make two opposit sides, to some extent, change from opposition to unification. This action has important practical significance: to cultivate the public's protection consciousness of language resources, to promote language harmony and safeguarding national security, to promote the construction of large database for language research and provide new ideas for the combination of teaching and scientific research, etc.Both at home and abroad, there have been a lot of theories about construction of a languge museum, but practices mainly go on in other developed countries and regions such as Europe and the United States. Domestic language museums mainly base on Web sites or network digital forms. The construction of a language museum which preserve and exhibiting the living languages ergengtly needs an organization to implement. In this context, Hezhou University has started he construction of a language museum, combinating of theory and practice of it.
\end{abstract}

\section{Project profile of language museum in Hezhou University}

Dialect is precious intangible cultural heritage and also cultural carrier. Linguistic diversity is an important condition for keeping cultural diversity. We try to set up local language museum in Hezhou where language resources are rich, utilize modern technical means to keep and display local rich linguistic data of dialects and verbal culture and summarize relevant experience in language museum construction. Under the guidance of the idea of "preserving and protecting language resources" , language research team and relevant departments of Hehzou University has gradually carried out construction of language museum through explorations for over 20 years. Because Hehzou University is in the northeast of Guangxi and at the boundary of Hunan and Guangdong, linguistic geographical distribution here is complex, which offers rich resource guarantee for museum construction. An effective approach of protecting linguistic and cultural diversity is to construct language museum in the region rich in language resource and preserve diversified active dialects. In terms of opportunities and challenges, multiple departments of the university started to propose preparations for language museum construction as early as 2012. Museum decoration stage came at the end of 2015. In the article of Exploration of Language Museum Construction Mode in Regions Rich in Language Resource ${ }^{[1]}$, we preliminarily introduce preconditions, preliminary scheme, implementation plan, problems and development prospect of language museum construction in Hezhou University. Here, we mainly talk about historical background and practical significance of museum construction.

\section{Historical background of language museum construction in Hezhou University}

Economic integration requires language unification, which directly impacts linguistic diversity. As modernization and urbanization advance, Chinese dialects and minority language are changing at an unprecedented speed. Many dialects are in imminent danger or are faced with extinction. The imminent danger of dialects will result in extinction of national culture and regional culture and bring about negative influence on Chinese culture inheritance and cultural diversity. Language museum construction conforms to the historical trend of protecting language resources. In such historical trend, 
many Chinese and foreign experts, scholars and governmental agencies carry out arduous theoretical and practical explorations for preserving and protecting linguistic diversity. Language museum construction is an important content.

\section{Theoretical exploration of language museum construction.}

There are numerous theoretical explorations about preserving endangered languages and language cultures in the way of language museum at home and abroad. David Graddol ${ }^{[2]}$ (2008) called language museum in conception “THE WORLD OF LANGUAGE” . His conception mainly involves four parts: the world of spoken language, the world of writing, the world of understanding and the world of language, its research and practice. Cao Zhiyun ${ }^{[3]}$ (2010) proposed the conception of constructing Chinese dialect museum and dialect eco-museum. Liang Changfu ${ }^{[4]}$ (2012) called on existing local museums to participate in dialect protection and considered "the work objects of a museum also include non-visible human cultural heritage except visible human cultural heritage. Local dialect as a mature and complete linguistic form which generates and develops in a region within a quite long historical period is an important organic component of human cultural heritage." $\mathrm{Xu}_{\text {Shixuan }}^{[5]}$ (2015) indicated that language museum as an interdisciplinary new thing crossed two disciplines: linguistics and museum science. Hence, we are required to have interdisciplinary cooperation. Zhang Xiaoming ${ }^{[6]}$ (2015) put forward a specific reference scheme for "exhibition content and display mode" of Shandong dialect. Green Book of Chinese Language Life Chinese Language Resource Survey Manual ${ }^{[7]}$ (2015) offers job norms for paper records, voice recording and picture recording in language protection project, so it can serve as the reference norm of language museum construction.

\section{Practical exploration of language museum construction.}

There are many practices about language museum building. At present, many foreign institutions such as European Union of Language Resources and American Language Data Consortium and even many communication operating merchants are developing music library to reserve endangered languages. It is understood that successful countries mainly include Britain and America etc. in terms of language reservation. Hans Rawson endangered language reservation project in School of Oriental and African Studies of University of London is one of the largest endangered language museums with the widest range, the most language types and the richest contents in the world. It has adopted high-tech digital means to reserve nearly 300 extremely endangered languages in the world. In America, National Foreign Language Resource Centre in University of Hawaii treasures up endangered languages of minority ethnic groups in Pacific Island. Local digital archive of University of Alaska collects language culture of local indigenous group. According to statistics of website of The Canadian Language Museum, about 35 language-themed museums in the world, and 2/3 of them are in Europe.

Although there is no museum which takes active language exhibition as the object in China, relevant language protection work is under way. In 2012, State Language Commission and Ministry of Education launched construction of audio database of Chinese language resources. So far, Beijing, Shanghai and Jiangsu etc. have completed audio database construction work. In May 2015, Chinese language resource protection project launched by Ministry of Education and State Language Work Committee was implemented in multiple regions, and massive language audio-video data were gathered. There are also some websites or network platforms with language museum functions, such as "multimedia data bank of Chinese dialect and culture" of Chinese Language Resource Protection Research Center, Language Resource Research Institution, School of Language Science, Beijing Language and Culture University; "Jiuzhou website" of Chinese Academy of Social Sciences: language resource network service platform; “dialect culture website" developed by dialect culture room at Chinese dialects research center of Ji'nan University; digital culture museum of Beijing language culture resources presided over by Zhang Weijia; Dongguan dialect archive presided over by Zhuang Chusheng and co-built with Dongguan Archives. In addition, there are many language websites or digital museums under construction, such as "dialect museum" that the host of Hunan TV Station - Wang Han plans and prepares to launch on mobile phone terminal 
(Hongwang 2013-11-3), and digital museum of endangered languages presided over by Fan Junjun from Ji'nan University and co-constructed by Guangdong Provincial Museum.

It's especially worth noting that some foreign institutions gather Chinese language resources very actively. A British institution subsidizes Chinese experts to help collect endangered languages in China, and many audio/video materials of languages have been gathered. “Xiangyinyuan” website sponsored by American people has attracted a large number of Chinese volunteers to offer Chinese dialect data. This move has aroused general attention and worries in the society. If foreign intelligence department supports and gets involved, this will result in the threat to China' s national security. Moreover, if language audio-video data gathered and recorded by Chinese experts are shared via network, language resources will be disclosed worldwide. From a perspective, this will threaten language security of China.

\section{Constructing and preserving active language museum is inevitable in historical development.}

In conclusion, language museum construction in China is mainly dominated by the form of websites or network digit. The language museum which takes active language as the exhibition object is still in theoretical exploration stage in China. In other words, there is no physical active language museum in China. Besides, although Jiangsu, other provinces and cities which have completed audio database construction have wide coverage, the density is insufficient of only one language point is gathered in a county. For the regions rich in language resources, many complex endangered dialects and especially unique local dialects fail to be gathered and preserved. Due to historical reasons, language resources in some regions of China are unusually rich. For example, Hezhou City is a prefecture-level city with a population of several million, but it owns 3 minority languages and over 20 sub-dialects which belong to 6 Chinese dialects. There are also specific local dialects. These characteristic local dialects are mostly in imminent danger, and they urgently need to be collected. It is significant to study how to construct a language museum in the regions rich in language resources so as to preserve and protect local language resources.

\section{Practical significance of language museum construction in Hezhou University}

\section{Cultivate public self-awareness of protecting language resources.}

The primary function of language museum is to record and preserve languages and cultural phenomena and leave very precious intangible cultural heritage for descendants through paper texts, audio and video recording. Based on recording and preservation, multiple art means are used to show languages to the public so that audiences can intensively experience aesthetic pleasure brought by linguistic and cultural diversity in the limited time and space. The government and the public need to jointly participate in language resource protection. The language museum can play the role of a bridge to connect the two. The whole society can focus on linguistic and cultural diversity in the museum. Thus, public self-awareness of language resource protection can be trained to maintain rich language cultures.

\section{Promote language harmony and maintain national language security.}

Harmonious coexistence of multiple languages or dialects represents harmonious coexistence of multiple ethnic groups with different cultural background. The language museum equally and intensively displays different languages or dialects in the limited space, which will undoubtedly give audiences inflection or edification of national equality and harmonious coexistence. In this way, equal, harmonious and secure cultural concept can spread, national psychology of harmonious coexistence Can be cultivated. Meanwhile, national unity and language harmony can be promoted. Local language museum has strong regionalism in terms of collecting linguistic data. Except exhibiting and sharing common linguistic data of major dialects on network, unique and characteristic endangered language dialect audio/video linguistic data should not be disclosed as museum collection. After these endangered language dialects disappear, they can be recovered according to audio/video and paper materials. This also guarantees the need of national language security. 


\section{Offer reference for big database construction for language research.}

At present, Chinese dialect research and national language research is mainly based on a single point or small-range field investigation materials. Few typology research scholars are mostly based on indirect paper materials during type comparison, so it is hard to verify conclusion reliability ion a large scale. The language museum intensively preserves language materials in multiple places, and paper, audio and video are applied at the same time. This will provide a concentrated simulation field for linguistic typology research and offer reference for big database construction for language research.

\section{Offer new thought for combining college teaching and scientific research.}

Because the language museum to be constructed in this topic takes the college as the unit. Teachers and students in the university are the most direct audiences and beneficiaries. We can utilize this platform to create strong nostalgia culture atmosphere for students, cultivate students' feeling for native language and native language culture and guide them to respect others' language and culture. On this basis, it is required to train students' language survey skills, consciously train the habit of paying attention to language culture phenomena, make research results serve for teaching and make discipline construction, scientific research and talent training gain organic unification in language museum construction and use.

\section{Conclusion}

Language dialect is a valuable intangible cultural heritage. Linguistic diversity guarantees cultural diversity. Economic globalization and integration directly erode this valuable heritage. The two constitute two contradictory aspects. The construction of language museum can make the contradiction to become uniform from opposition, and has practical significance for training self-awareness of the public to protect language resources, promoting language harmony, maintaining national language security, facilitating big database establishment for language research and offering new thought for combining college teaching and scientific research. There are many discussions at home and abroad on the theory of language museum construction, but the practice is mainly imolemnted in Europe, America, other developed countries and regions. Language museum construction in China is mainly based on the forms of websites or network digit. Some units or organizations need to boldly implement the construction of language museum which takes active language exhibition as the object. In such background, Hezhou University will make contributions to the research on combining the theory and practice of language museum construction.

\section{References}

[1] Liu Zongyan, Deng Yurong, Exploration of Language Museum Construction Mode in Regions Rich in Language Resource--Case Study of Language Museum in Hezhou University, Journal of Hezhou University, 2016 (1).

[2] Anthony Mill Llana, Home of language: world active language museum, Chinese version of Museum International, Yilin Press, 2008 (3).

[3] Cao Zhiyun, Conception on construction of Chinese dialect museum, Linguistic Researches, 2012 (2).

[4] Liang Changfu, Effective support of local museum on protection and inheritance of local dialect, Popular Science \& Technology, 2012 (8).

[5] Xu Shixuan, Museum in language and language museum--on construction of endangered language collection and language museum, Journal of Yuxi Normal University , 2015 (5).

[6] Zhang Xiaoming, Study on dialect museum exhibition strategy, Journal of Shandong University of Technology, 2015 (2). 
[7] Language Text Information Management Department under Ministry of Education, China Research Center of Language Resource Protection, Green Book of Chinese Language Life Chinese Language Resource Survey Manual. Beijing: Commercial Press, 2015. 